\title{
A VERDADE DE PALAVRA EM YVES BONNEFOY E MARCELINE DESBORDES- VALMORE
}

Guacira Marcondes Machado Universidade Estadual Paulista - Araraquara

Y ves Bonnefoy (1923) não é um poeta de fácil leitura. Com frequência, os críticos reportam-se a seus ensaios críticos seus poemas e, também, a seus poemas para tornar preciso o sentido de seus ensaios.

Em 1992, ele publicou um livro de ensaios críticos intitulado Vérité de parole et autres essais no qual aborda a obra de alguns poetas em que reconhece a existência de proximidade com sua própria obra. Este é o caso da poesia de Marceline Desbordes-Valmore (1786-1859), no primeiro dos estudos que apresenta, e no qual quer mostrar, como diz, de que maneira foi conquistada a primeira voz autêntica da poesia feminina nos tempos modernos, na França.

No sentido de tornar compreensível essa proximidade, recorreremos a uma curta introdução à obra de Bonnefoy, na qual se teria um pouco o conjunto de suas posições principais em relação ao ato poético. O texto de Jean-Michel Maulpoix Introduction à la lecture de l'oeuvre d'Yves Bonnefoy ${ }^{1}$ apresenta rapidamente a obra do poeta, e dele extrairemos fragmentos que sirvam a esse propósito. Segundo Maulpoix, é importante

${ }^{1}$ MAULPOIX, 2005. 
saber que Bonnefoy busca não se deixar iludir pelos jogos e pelas facilidades da linguagem, pelo desejo de infinito, pelo que há de mágico e de angelical no discurso sobre a poesia, tudo isso que é tributário de uma mitologia romântica da criação poética. Bonnefoy resiste a fazer da poesia um universo separado do real, autossuficiente, autárquico. Mas não nega o desejo de imagens, o apetite da fantasia, a necessidade do absoluto, da plenitude da experiência poética. Ele procura uma justa postura, que leve em conta os aspectos contraditórios da experiência humana e de sua personalidade, dividida entre materialismo e transcendência. A experiência poética, para o poeta, é lugar de exercício espiritual: ao invés de fugir para a fantasia, a poesia gostaria de se propor como uma iniciação à própria realidade.

De seu contato com o surrealismo, desde a adolescência, ele reteve a noção de que a poesia está ligada a uma intensificação da consciência e da palavra. Importante na sua reflexão e na sua poesia, também, é o fato de que Bonnefoy faz a crítica do conceito - que é a noção pura, separada da realidade, e que leva a linguagem ao máximo de seu poder de abstração. Ele recusa o conceito como inteligibilidade separada das coisas, abstração estranha ao sensível, ao humano: o conceito congela a linguagem. Daí seu antiplatonismo: ele não busca o ser para além do sensível, mas na sua própria aparência. O objeto é este, pois as coisas daqui pesam mais na mente do homem do que as ideias perfeitas. À linguagem petrificada do conceito, Bonnefoy vai opor uma certa flutuação da palavra poética nas vizinhanças do inominável.

Lembra ainda Maulpoix que presença é a palavra-chave da poética e do pensamento de Yves Bonnefoy. Espécie de síntese entre o real e o surreal, é uma postura existencial. Em Arrière pays, o poeta diz: "Eis o mundo sensível. A palavra, que é o sexto e o mais forte sentido, deve ir a seu encontro e decifrar seus sinais. É dessa tarefa que eu gosto." ${ }^{2}$

${ }^{2}$ BONNEFOY apud MAULPOIX, 2005, tradução nossa. 
Há também a ideia de verdadeiro lugar - o país é o contrário do conceito. Ele situa-se na intersecção quimérica do real e do irreal, do aqui e do alhures, do relativo e do absoluto. Bonnefoy opõe verdade de palavra a palavra de verdade: como o ser falante pode proteger, salvaguardar (até na palavra) "alguma coisa do modo de ser da origem?"3 A verdade de palavra é uma proximidade das realidades essenciais...

Lembramos, agora, que uma de suas últimas publicações, de 2001, é Les Planches courbes ${ }^{4}$, na qual ele volta à infância, paraíso perdido, para fazer-lhe homenagem, por considerá-la um período de grande intensidade da vida humana. Poesia de grande simplicidade,é também um hino à vida, em seu contato primário, natural, material com o mundo que nos cerca. A infância sugere a novidade, o maravilhar-se com tudo o que se percebe, postura que deve ser também a do poeta.

Em seu ensaio crítico sobre Marceline Desbordes-Valmore ${ }^{5}$ - poeta que viveu entre 1786 e 1859 - é pela infância, justamente, que ele inicia. Nascida em Douai, na Flandres francesa, o poeta lembra a felicidade que ela conheceu nessa cidadezinha, então cercada de trigo e de bosques, e onde o som dos sinos ajudou a deixar nela a ideia de felicidade que decorre das coisas simples, dos trabalhos cotidianos e de vidas sem surpresas. E detendose, ainda, naquilo que também atrai a ele, Bonnefoy cita o gosto pelo cultivo dos jardins, a companhia da árvore ou do rio, a parreira, mas também, a moringa ou o móvel que brilha na penumbra. Nessa verdadeira "escuta precisa da natureza" como ele diz, Marceline menciona coisas que nesse momento da infância ainda estão juntas, ou em relação de contiguidade, de simultaneidade na qual, aliás, nós mesmos, seres humanos,

${ }^{3}$ BONNEFOY apud MAULPOIX, 2005, tradução nossa.

${ }^{4}$ BONNEFOY, 2001.

${ }^{5}$ BONNEFOY, 1992.

${ }^{6}$ BONNEFOY, 1992, p. 11. 
somos recebidos em uma só presença. Ora, lembra Bonnefoy, todo esse mundo irá se perder, a partir do momento em que se falar dele por meio de palavras, porque por um trabalho de pensamento, todas as coisas serão classificadas e separadas, o que fará com que seja abandonado esse estado primeiro, puro e simples, da experiência do lugar, e que conheçamos a angústia que nasce com a linguagem - com o conceito.

Bonnefoy lembra rapidamente a história da vida de Marceline, repleta de acontecimentos extraordinários, excepcionais a partir de seus 15 anos, quando sai da França com a mãe e deve voltar, meses depois, sozinha, em uma viagem marítima cheia de perigos.É fácil compreender os efeitos desses acontecimentos sobre a jovem, que se tornou bastante aguerrida, com a sensibilidade e a consciência bastante aguçadas, e teve amadurecida pelo excesso de experiências a sua vocação poética. Ao voltar à França, ela se apresentou no teatro de Douai, como atriz de segundos papéis, depois em Rouen e, finalmente, em Paris. Seus primeiros poemas datam de 1813, época que sucede a uma experiência amorosa com o também ator e escritor, bastante considerado então, Henri de Latouche. E foi grande, observa Bonnefoy, a dificuldade que Marceline teve que enfrentar ao se tornar poeta. Pelo fato de ser mulher, só esperavam dela uma obra sem originalidade e inferior. Em uma sociedade na qual os homens decidem os valores, as ideias, as percepções, os projetos que dão estrutura à língua, somente eles são livres para um ato de palavra no qual a mulher é apenas objeto. Sendo assim, o grande obstáculo para Marceline, sendo mulher, era a linguagem. Reflete Bonnefoy, no entanto, que só mesmo a língua poderia aproximar o homem da mulher, mas em um outro estado mais aberto a aspectos simples da realidade natural, como já o sabiam poetas como Wordsworth, Hölderlin, Nerval, todos contemporâneos de Marceline Desbordes-Valmore, mas que não tinham grande público. 
Nesse início do século XIX, na França, a poesia versificada será reconhecida e acolhida toda vez que o poeta, como Marceline, tiver ardor e sentimentos. Ela iniciou-se por elegias e fábulas ao gosto clássico, de um classicismo já gasto, mas aos poucos, de livro em livro, elaborou, de maneira irregular, mas cada vez mais densa, um discurso sem dúvida menos ambicioso que o dos grandes poetas da geração romântica, mas tão emocionante quanto o deles, infinito em suas vibrações e, frequentemente, muito mais verídico. Bonnefoy acredita que sua vida com o marido - o medíocre ator Valmore, com quem teve quatro filhos-, as mudanças constantes de cidade, as preocupações materiais, a doença e a morte das três filhas lhe trouxeram ansiedade e alarmes, mas, também, a possibilidade de uma reflexão poética que direcionou sua poesia para ser esplêndida.

O que foi essa poesia produzida por Marceline DesbordesValmore de 1830 a 1850? Em sua reflexão crítica, Bonnefoy encontra nela, fazendo sua diferença, mesmo sem desejo aparente de composição, uma espécie de luz, como se as palavras achassem a intensidade, a evidência que existiria potencialmente em cada coisa, um verso e outro, e depois outro se desprendendo da meditação e da lembrança e iluminando com um raio o horizonte inteiro da terra.

Bonnefoy ${ }^{7}$ cita alguns exemplos dessa impressão extraordinária de presença que se desprende, mesmo se distantes, de lugares evocados, de seres rememorados:"Jours heureux pleins de bruits que nuls bruits ne défont" (La Maison de ma Mère); "On ressemble au plaisir, sous un chapeau de fleurs" (Le chien d'Olivier); "toute buissonnière en un saule cachée" (La fileuse et l'enfant); "Mon âme encore oiseau rasait les jours mouvants" (Laisse-nous pleurer) ${ }^{8}$. E a causa dessa impressão de

${ }^{7}$ BONNEFOY, 1992, p.25.

8 "Dias felizes plenos de ruídos que nenhum ruído desfaz (La Maison de 
presença é, sem dúvida, o amor. Marceline renunciou à busca do sublime, do excepcional, preferindo aquilo que existe, na sua condição mais cotidiana. Mas, segundo a visão de Bonnefoy, aquilo que é, que existe, embora precário e limitado, ou talvez por causa disso mesmo, participa da unidade do universo, da vida que é recusada às criaturas da imaginação. $\mathrm{E}$ a unidade é luz. Ora, pergunta o poeta, em poesia, o que mais se pede? Nesse movimento de adesão levado a seu termo, que é silêncio, haverá a simplicidade e a proferição soberana. É o que se pode chamar de encarnação, e Bonnefoy acredita que esse acordo, por meio das palavras, entre existência e mundo, já se esboçava nas primeiras obras de Marceline, mesmo antes das elegias, em obras que falam de pastores, riachos, crianças que brincam nos campos. Trata-se de banalidades pastoris, em muitos aspectos fora de moda, mas que permitem o clarão da memória infantil, reavivando a cor de uma fita ou de uma coroa de plantas, e mostrando que as pastorais do século XVIII deram continuidade, de maneira discreta, ao antigo olhar ontológico que se procura, desde Virgílio, sob o signo da idade de ouro.

O segundo movimento de Marceline, reconhece Bonnefoy, é o de lançar-se em direção aos outros seres para levar-lhes a mensagem. É o que faz exemplarmente em um de seus mais belos poemas e um dos mais conhecidos, Les Roses de Saadi, de Poésies inédites':

ma Mère) ;"Parecemos ter prazer, sob um chapéu de flores" (Le Chien d'Olivier); "às aulas faltando escondida num salgueiro" (La fileuse et l'enfant); "Minha alma ainda um pássaro tocava nos dias moventes" (Laisse-nous pleurer). (BONNEFOY, 1992, p.25, tradução nossa).

${ }^{9}$ DESBORDES-VALMORE, 1860a. 
J'ai voulu ce matin te rapporter des roses;

Mais j'en avais tant pris dans mes ceintures closes

Que les noeuds trop serrés n'ont pu les contenir.

Les noeuds ont éclaté. Les roses envolées

Dans le vent, à la mers'en sont tout esallées.

Elles ont suivi l'eau pour ne plus revenir;

La vague en a paru rouge et comme en flammée.

Ce soir, ma robe encore en est tout embaumée...

Respires-en sur m'oil odorant souvenir. ${ }^{1011}$

Lembramos, rapidamente, que Sadi foi um poeta persa do século XIII, que escreveu, em 1259, o Gulistan ou O Jardim de Rosas, livro que se revelou muito influente em todo o Oriente. Trata-se de uma coletânea de poemas, apresentada como uma coleção de rosas diferentes em um jardim de rosas, e que contém histórias pessoais, aforismos, conselhos e reflexões humorísticas: uma antologia do saber-viver e do amor. Em nota no estudo crítico de Marceline, Bonnefoy ${ }^{12}$ observa que nos poemas de Sadi é um homem que sonha com rosas que

10 Quis, de manhã, trazer-te as rosas que colhi, Porém tantas eu pus nos cintos que cingi

Que os apertados nós não puderam contê-las.

Rebentaram os nós.As rosas que voaram

No vento para o mar juntamente rumaram...

Depois, seguiram a água e não voltei a vê-las.

Tomando rubra cor, as vagas se inflamaram:

E as minhas roupas, ah, o quão se perfumaram...

É noite, sente em mim o saudoso odor delas.

${ }^{11}$ (DESBORDES-VALMORE, 2002, p.42).

${ }^{12}$ BONNEFOY, 1992, p. 27. 
deixa suas vestes (robe em francês) perfumadas. Mas esse termo -robe (vestido), em francês, lembra ele também, traz sugestão "irresistivelmente feminina", que Marceline deve ter reconhecido de instinto e assumido.

Bonnefoy coloca suas concepções poéticas na interpretação do poema ao dizer que, nele, aquela que diz "eu" só pôde perceber a beleza e a abundância das flores por uma intimidade com a realidade sensível, que a maioria de nossas palavras sempre apaga de nosso campo de consciência. Ela fala dos "cintos" que não puderam "contê-las" - e isso é bem, entre o ser do mundo e nós, a interposição da linguagem, cujos "nós" estariam "rebentados". Imagens soberbas, diz Bonnefoy, para preservar sem machucar duramente a plenitude da origem.

Na casa de Douai, da infância de Marceline, havia apenas rosas, e essa "manhã" das "Rosas de Saadi" indica o primeiro tempo da percepção, segundo Bonnefoy, ainda uma referência que ela faz a seus primeiros anos. Além disso, o poema lembra que as rosas voaram no mar - mar que esteve tão presente no drama que ela viveu logo que saiu da infância.

Continuando sua leitura, Bonnefoy afirma que o vento que as carrega não é o da tempestade no mar, quando sua mãe já estava morta. Baseia-se em observação da poeta que, certa vez, disse que, com a mãe morta, ela levava um "negro" cinto do luto. Por isso, Bonnefoy acha que no poema há indícios de uma época de sonhos da adolescência e não o presente puro da percepção. Em profundidade, o acontecimento da ruptura que Les Roses de Saadi rememora não é a perda do imediato que a linguagem provocaria, mas sim o da relação plena - suficiente, sem imaginário - que ligara a criança, outrora, a uma realidade que era um lugar organizado, mediatizado, uma terra.

O poeta, então, louva essa simplicidade, essa espontaneidade do movimento que vai em direção ao outro com o dom dessa riqueza que é a lembrança. Com o imaginário 
do romantismo, o Ocidente, a modernidade alteraram a relação com o simples, e a palavra não é mais a evidência. Mas as coisas continuam sempre lá, o jardim guardou suas formas e talvez, amanhã, outras jovens entrarão nele: a poesia tem o poder de lhes permitir isso, se soubermos respirar em sua roupa, como diz a poesia - "minhas roupas [...] se perfumaram", que é, em francês, a "odorante lembrança" do mundo. Não são as palavras, diz Bonnefoy, que se enganam, mas o falante que as submete à sua imaginação, as dobra à sua solidão. Portanto, entreguemo-nos aos outros seres, o que dissipará nossos sonhos, nossas fantasias, e tornará o mundo visível. Aqui, no poema de Marceline, o sujeito só existe pelo impulso que o consagra ao outro, a palavra é uma oferta, uma prece, uma troca. E nós passamos a pensar - o que é o próprio coração do poético - em um outro estado da linguagem, incitado por esse dom que seria mútuo. Por que não poderia acontecer uma língua de "nós" mais soltos, que soubesse nosso lugar?Reinventar esse lugar como queria Rimbaud, lembra Bonnefoy; reavivar as cores que passam do ser-no-mundo - e foi isso que Wordsworth constatou, inquieto -, quando a criança se torna pouco a pouco um ser racional.

O projeto de uma poesia absolutamente moderna está em um longo poema de Marceline Desbordes-Valmore, que Bonnefoy reputa celeste pelo exemplo de amplitude da experiência possível. Trata-se de Rêve intermittent d'une nuit triste $^{13}$, publicado em 1860, escrito por ela após adormecer à cabeceira da filha, à beira da morte. Ao acordar, então, rabiscou o poema que, diz o poeta, não é um sonho, mas a própria realidade que se descobre nas plantas e riachos, nos verdes prados de que desfrutam e onde pastam os animais do solo natal:

${ }^{13}$ DESBORDES-VALMORE, $1860 \mathrm{~b}$. 
Rêve intermittent d'une nuit triste

Ô champs paternels hérissés

Où glissent le soir des flots de jeunes filles!

Ô frais pâturage où de limpides eaux

Font bondir la chèvre et chanter les roseaux!

Ô terre natale! à votre nom que j'aime, Mon âmes'en va toute hors d'elle-même;

[...]

Voilà mon berceau, ma colline enchantée

Dont j'ai tant foulé la robe veloutée,

Pourquoi je m'envole à vos bleus horizons, Rasant les flots d'or des pliantes moissons. ${ }^{14} 15$

Cada uma dessas figuras do mundo simples que brilha por seu nome revelando a Marceline, livre por instantes de sua

14 Sonho intermitente de uma noite triste

Ó campos paternos erguidos

Onde deslizam à tarde ondas de jovens

Ó frescas pastagens onde límpidas águas

Fazem saltar a cabra e soar o caniço,

Ó terra natal! a seu nome que amo

Minh'alma corre em transporte;

[...]

Eis meu berço, colina encantada

De que tanto pisei a veste aveludada,

Porque alço voo aos azuis horizontes

Roçando o ouro das ondas das messes vergadas.

${ }^{15}$ (DESBORDES-VALMORE, 1860b, tradução nossa). 
infelicidade, aquilo que somos, sem querer compreendê-lo: uma das pequenas coisas que formam o todo, uma "étincelle d'or de la lumière nature", sentindo para além das lágrimas, uma alegria, a experiência do absoluto. O sono contribuiu para soltar inteiramente algumas palavras que estão sempre mais próximas do mundo e apresentam como que sua soleira. Por sua vez, essas palavras, pura poesia, têm um valor que ultrapassa sua autora, e brilham para nós como uma promessa.

Esse poema, que é um sonho "intermitente", diz Bonnefoy, porque só podemos ficar de maneira duradoura no pressentimento da plenitude terrestre, é na verdade um poema extraordinário, nos limites quase que ultrapassados da poesia ocidental. Os animais, de olhos muito abertos, ficam perto dos homens entre flores e árvores como em um mosaico dos primeiros séculos; as cores têm uma fosforescência que remete a Runge, a Blake e, também, às iluminuras persas que falam do paraíso:

La vache mugit sur votre pente douce,

Tant elle a d'herbage et d'odorante mousse,

Et comme au repos appelant le passant,

Le suit d'un regard humide et carressant!

Jamais les bergers pour leurs brebis errantes

N'ont trouvé tant d'eau qu'à vos sources courantes.

J'y rampai débile en mes plus jeunes mois,

Et je devins rose au souffle de vos bois.

[...]

Car la liberté toute riante et mûre

Est là, comme aux cieux, sans glaive, sans armure,

Sans peur, sans audace et sans austérité

Disant:"Aimez-moi, je suis la liberté!

[...] 
Ô patrie alsente! Ô fécondes campagnes, Où vin rents'asseoir les ferventes Espagnes!

Antiques noyers, vrais maîtres de ces lieux, Qui versez tant d'ombre où dorment nos aïeux?

Échos tout vibrants de la voix de mon père Qui chantait pour tous:"Espère!espère!espère!1617
A vaca mugindo em sua encosta suave,
De tanto pasto e musgo perfumando,
Como que chamando o passante ao repasto
O segue com olhar úmido e caricioso

Nunca os pastores para suas ovelhas errantes

Encontraram tanta água como em suas fontes correntes.

Nela arrastei-me fraca em meus jovens meses

E tornei-me rosada ao sopro de seus bosques

[...]

Pois a liberdade risonha e madura

Está aí, como nos céus, sem gládio, sem armaduras,

Sem medo, sem audácia e sem austeridade

Dizendo: "Amem-me, eu sou a liberdade!"

[...]

Ò pátria ausente! Ó campos fecundos

Onde vieram sentar-se as ferventes Espanhas!

Antigas nogueiras, mestres reais desses lugares, Que jogam tanta sombra onde dormem os antepassados?

Ecos vibrantes da voz de meu pai

Que cantava a todos: “Espere! espere! espere!"

${ }^{17}$ DESBORDES-VALMORE, 1860b, tradução nossa. 
Para Bonnefoy, nesses versos, estamos próximos daquilo que Corbin chamava de mundo imaginal, a terra celeste. A dor que não se exprimiu na poesia clássica e foi utilizada pelo romantismo em seu teatro do "eu" revela-se um dos agentes dessa alquimia que Baudelaire estudou em Marceline, que ele admirava. Além disso, a estrutura métrica, essa sequência de dísticos, avança, silenciosa, até o verso de onze pés que Verlaine e Rimbaud irão descobrir também. Mas, em Marceline, é um dos grandes caminhos que se abrem ao discurso, para além das estruturas fechadas. E o sonho, como tal, esse fermento de toda escrita, mas , também, esse perigo da poesia, afirma-se aqui, finalmente, em sua virtualidade não reconhecida, embora a mais elevada, que é de não mais servir o desejo, mas trabalhálo, livrá-lo do engodo das satisfações parciais, mostrar o todo, a terra em sua unidade.

Para Bonnefoy, se hoje, ainda, não foi reconhecida toda a qualidade poética de Marceline, é que, por razões de generalização comum e de parentesco de vocabulário, ela continua a ser lida à luz das proposições, dos valores e das conquistas do romantismo, o qual permaneceu na França como exemplo de uma poesia profundamente masculina, mitológica, portanto, fechada à sua tentativa de ultrapassagem dessa forma. Para Bonnefoy, ainda, Marceline é romântica no mesmo sentido em que William Blake, Wordsworth e Nerval puderam sê-lo, pois tiveram o sentido da suficiência terrestre. Mais exatamente, é no Rimbaud de Une saison en enfer, quer o poeta, que se deve buscar a maior proximidade com Marceline, porque ambos falam do que existe e não do que se sonha, porque sabem, entre poucos, que a poesia deve conservar nas palavras um valor de troca.

Finalmente, Bonnefoy lembra que Marceline DesbordesValmore se dirige com frequência ao Deus criador que decidiu seu destino, e é o pai que, para ela, não pode ser nem Juiz, nem 
Lei. Ora, se ela foi poeta, graças a essa adesão a uma terra, a um lugar que permaneceu nela da infância, foi colocando no local de suas lembranças, como se fosse sua fonte e mesmo sua prova, uma figura de pai que lhe deu a coragem de romper a terra, sob as estrelas, e que era, para ela, aquele que a carregara, que a reconhecera, fazendo-a conhecer a solidariedade instintiva, $\mathrm{o}$ dom de reciprocidade, o puro amor.

\section{Referências bibliográficas}

BONNEFOY,Yves. Les planches courbes. Paris: Gallimard, 2001. (Collection Poésie, 384).

. Vérité de parole et autres essais. Paris: Mercure de France, 1992.

DESBORDES-VALMORE, Marceline. Les roses de Saadi. In: Poésies inédites,1860a. Disponível em:

<http:/ / poesie.webnet.fr/lesgrandsclassiques/poemes/marceline_ desbordes_valmore/les_roses_de_saadi.html >. Acesso em: jan. 2014.

. Rêve intermittent d'une nuit triste. In: . Póesies inédites. 1860b. Disponível em: <http:/ / www.poetes.com/aut_rom/d_reve. htm>. Acesso em: jan. 2014.

. Les Roses de Saadi. In: Pequena Antologia de Poemas Franceses. Concepção e tradução de Renata Cordeiro. São Paulo: Ed. Landy, 2002. MAULPOIX, Jean-Michel. "Introduction à la lecture de l'oeuvre d'Yves Bonnefoy". Jean-Michel Maulpoix e Cia, 2005. Disponível em: <www.maulpoix.net/Bonnefoy.htm>. Acesso em: jan. 2014. 


\section{Resumo}

Neste texto, procura-se expor o estudo crítico, realizado por Yves Bonnefoy, da poesia de Marceline Desbordes-Valmore. Nele, ao mesmo tempo em que faz uma análise da obra da poeta do romantismo francês, Bonnefoy dá a conhecer suas próprias posições em relação ao ato poético.

\section{Résumé}

Ce texte cherche à montrer l'étude critique réalisée par Yves Bonnefoy de la poésie de Marceline Desbordes-Valmore. En même temps qu'il fait une analyse de l'oeuvre de la poète du romantisme français, Bonnefoy fait connaître ses positions mêmes en ce qui concerne l'acte poétique. 
